\title{
Primer Sezaryen Doğum Oranını Etkileyen Faktörler
}

\author{
Mehmet BÜLBÜL
}

Adıyaman Üniversitesi Tıp Fakültesi, Kadın Hastalıkları ve Doğum Anabilim Dalı, Adıyaman.

\section{ÖZET}

Bu çalışmada artan sezaryen doğum (SD) oranlarının sebeplerinin araştırılması amaçlanmıștır. Hastanemizde 2014-2017 yılları arasında tek bir hekimin sorumluluğunda doğum yapan kadınlar retrospektif olarak değerlendirildi. SD oranları ve nedenleri araştırıldı. Bu süre içinde 3488 doğum gerçekleşti. Bunların 2108'i (\%60,4) vajinal doğum, 1380'i (\%39,6) SD idi. SD’ların yaklaşık yarısı (\%49,6) primer SD (PSD) idi. Hiçbir hastaya isteğe bağlı SD yapılmadı. PSD oranı \%19,6 olarak saptandı. PSD olan kadınların \%61,5 nullipar, \%38,5'i multipardı. Multipar gebelerde en sık PSD endikasyonları sırasıyla fetal distres $(\% 23,9)$, uzamış eylem $(\% 14,8)$ prezentasyon anomalisiydi $(\% 14,5)$. Nullipar gebelerde ise uzamış eylem $(\% 28,5)$, fetal distres $(\% 21,4)$ ve baş pelvis uyuşmazlığ $(\% 18,8)$ en sık nedenlerdi $(p<0,05)$. Ayrıca zaman içinde SD oranlarında bir miktar artış saptandı. Sonuçlarımıza göre isteğe bağlı SD yapılmadığında, tüm sevkleri alan tersiyer bir merkezde bile PSD oranı \%19,6 civarındadır. PSD’ların en sık sebebi uzamış eylem, fetal distres, baş pelvis uyuşmazlı̆̆ı ve perzentasyon anomalisiydi. Sadece ihtiyacı olan kadına SD uygulamak hem PSD hem de mükerrer SD oranlarını azaltacaktır.

Anahtar Kelimeler: Primer sezaryen doğum. Endikasyon. Risk faktörleri. Sezaryen doğum oranları.

Factors Affecting Primary Cesarean Delivery Rate

\begin{abstract}
In this study, it was aimed to investigate the causes of increasing cesarean delivery (SD) rates. Women who gave birth under the responsibility of a single physician in our hospital between 2014-2017 were evaluated retrospectively. SD rates and causes were investigated. During this time, 3488 births occurred. Of these, 2108 (60.4\%) were vaginal delivery, 1380 (39.6\%) were SD. About half (49.6\%) of SD were primary SD (PSD). Optional SD was not applied to any patient. The rate of PSD was found to be 19.6\%. 61.5\% of women with PSD were nulliparous and $38.5 \%$ were multiparous. The most common PSD indications in multiparous pregnant women were fetal stress (23.9\%), prolonged labor (14.8\%) presentation anomaly (14.5\%), respectively. In nulliparous pregnant women, prolonged labor (28.5\%), fetal stress $(21.4 \%)$ and head pelvis incompatibility $(18.8 \%)$ were the most common causes $(p<0.05)$. According to our results, the PSD rate is around $19.6 \%$ even when optional SD is not made. The most common causes of PSD were prolonged labor, fetal stress, head pelvis incompatibility, and presentation anomaly. Applying SD only to women in need will reduce both PSD and recurrent SD rates.
\end{abstract}

Key Words: Primary cesarean delivery. Indication. Risk factors. Cesarean delivery rates.

Günümüzde en sık yapılan cerrahi prosedürdür olan sezaryen doğum (SD), uygun endikasyonlarla yapıld1ğında anne ve bebek için hayat kurtarıcı cerrahi bir prosedürdür. Fakat tıbbı endikasyon dişında SD uygulamanın anne ve bebek için kanıtlanmış bir faydası yoktur. Aksine, anestezi riskleri, mesane ve barsak yaralanmaları, yenidoğanın geçici takipnesi, plasenta

Geliş Tarihi: 21.Şubat.2021

Kabul Tarihi: 19.Nisan.2021

Dr. Mehmet BÜLBÜL

Adıyaman Üniversitesi Tıp Fakültesi,

Kadın Hastalıkları ve Doğum Anabilim Dalı,

Adıyaman.

Tel: 05323083455

E-posta: mehmetbulbulmd@gmail.com

Yazarların ORCID ID Bilgisi:

Mehmet BÜLBÜL: 0000-0001-5695-2586 adezyon anomalileri, uterus rüptürü, batın içi yapışıklıklar gibi SD'a özgü risklerin artmasına neden olarak anne ve bebek için morbidite ve mortalite riskini artt1rabilir. Bundan dolayı sadece tıbbı gereklilik durumunda yapılması gerekmektedir ${ }^{1}$.

Günümüzde gelişmiş ülkelerde doğumların $1 / 3$ 'ü $\mathrm{SD}$ ile gerçekleştirildiği bilinmektedir ${ }^{2}$. Bu oranlar bazı ülkelerde daha yüksektir ve dünya genelinde giderek artmaktadır $^{3}$. Bu artışta birçok faktör rol oynayabilir. SD endikasyonlarının artmış olması, antepartum takipteki gelişmeler, hastanın SD isteği, perinatal mortalite ve pelvik relaksasyona karşı koruyucu olduğu düşüncesi ve doğumun planlanabilmesi bu sebepler arasında sayılabilir.

Bir gebenin ilk kez SD ile doğum yapması, primer sezaryen doğum (PSD), daha önce SD yapmış gebenin tekrar SD ile doğum yapması mükerrer SD olarak adlandırılmaktadır. Bunlardan SD doğum oranının artmasına en çok katkı sağlayan faktör PSD dur 
Bundan dolayı SD oranlarını azaltabilmek için PSD yapılan kadınların incelenmesi ve önlenebilecek nedenlerin saptanarak engellenmesi daha doğru olacaktır Geçirilmiş uterin cerrahi, prezentasyon anomalisi, başpelvis uygunsuzluğu, fetal distres gibi birçok tıbbı nedenle PSD yapılsa da gebenin vajinal doğuma hazırl1ksız olması ve korkması, hekimlerin malpraktis korkusu, çok yoğun çalışma koşulları, hasta uyumsuzluğu gibi nedenler PSD oranlarını arttırabilmektedir. $\mathrm{Bu}$ çalışmada üçüncü basamak sağlık hizmeti veren bir hastanede PSD oranlarını etkileyen faktörleri belirleyerek bunlara karşı alınabilecek önlemler tartışıldı.

\section{Gereç ve Yöntem}

Retrospektif vaka kontrol çalışması olarak planlanana bu çalışmaya yerel etik kurulu onayı alındıktan sonra (karar no: 2018/9-17) başland1. Üçüncü basamak tedavi merkezi olan bir üniversite hastanesinde, 01.01.2014 ile 31.12.2017 tarihleri arasında doğum yapan gebelerin verileri incelendi.

Dahil edilme kriterleri: Bu çalışmada daha standart sezaryen doğum endikasyonları elde edebilmek için, üçüncü basamak bir sağlık merkezinde asistan eğitimi başlamadan önce tek bir hekime ait doğumlar çalışmaya dahil edildi. Bu tarih aralığında doğumların hiçbirinde isteğe bağlı elektif SD yapılmadı.

Hariç tutulma kriterleri: Obstetrik nedenler dışında değiştirilemeyen nedenlerden dolayı SD yapılan 7 hasta çalışma dışı bırakıldı (glokom tanısıyla iki gebe, geçirilmiş rektovajinal fistül operasyonu nedeniyle bir gebe, pulmoner hipertansiyon nedeniyle bir gebe, kalp yetmezliği nedeniyle bir gebeye ve kalp kapak hastalığ1 nedeniyle 2 gebe).

Amerikan Kadın Hastalıkları ve Doğum Uzmanları Koleji (ACOG) 2014 kılavuza uygun olacak şekilde sadece obstetrik sebeplerle (fetal distres, prezentasyon anomalisi, ilerlemeyen eylem, çoğul gebelik, fetal makrozomi, Baş pelvis uyuşmazlığı, kordon sarkması, plasentasyon anomalisi) SD ile doğum tercih edildi ${ }^{5}$.

Doğum yapan kadınların sosyo-demografik verileri, obstetrik özellikleri ile doğuma ait verileri (gebelik haftası, fetüs sayısı, gebelik haftası, doğum şekli, bebeğin kilosu, cinsiyet gibi) kayıt edildi. SD oranı = (SD sayıs1/Toplam doğum sayıs1)x100 formülüyle hesaplanırken, PSD oranı ise $=($ PSD sayıs1/ Toplam doğum sayısı)x100 formülüyle hesaplandı. Ayrıca yıllara göre SD oranları analiz edildi. Robson sınıflandırması ilk defa tarif edildiği gibi yapıldı ${ }^{6}$.

\section{İstatistiksel Analiz}

İstatistiksel analiz için SPSS sürüm 21 (IBM, Chicago, IL, ABD) kullanıldı. Sürekli değerlere sahip verilerin normal dağılıma uyup uymadığını belirlemek için Kolmogorov-Smirnov testi kullanıldı. İki grup arasın- daki farklılıkları belirlemek için normal dağılıma uyan veriler bağımsız örneklem t testi ile, normal dağılıma uymayan veriler ise Mann-Whitney $U$ testi ile değerlendirildi. Normal olarak dağılan değişkenler ortalama \pm Standart sapma olarak tanımlandı ve normal dağılıma sahip olmayanlar medyan (min-maks) olarak temsil edildi. $p<0.05$ istatistiksel olarak anlamlı kabul edildi. Kategorik değişkenlerin karşılaştırması ki-kare testi kullanılarak yapıldı.

\section{Bulgular}

Belirtilen tarih aralığında toplam 3488 doğum gerçekleşti. Bu doğumların 2108'i $(\% 60,4)$ vajinal doğum ile gerçekleşirken 1380'i $(\% 39,6)$ SD ile gerçekleşti (Tablo I, Şekil 1). Vajinal doğum ve SD kendi arasında karşılaştırıldığında ortalama anne yaşı ve eğitim süreleri SD grubunda daha yüksekti (sırasiyla $28,3 \pm 6,6$ vs $30,1 \pm 6,9$ yıl, $\mathrm{p}<0,001 ; 8,2 \pm 3,2$ vs $8,9 \pm 3,5$ $\mathrm{y} 1, \mathrm{p}=0,001)$. Gravida ve abortus sayıları her iki grupta benzerdi. Ölü doğum sayısı SD grubunda daha yüksek iken (0 (min: 0 - max: 3 ) vs 0 (min: 0 - max: 2), $\mathrm{p}=0,002$ ), ortalama doğumdaki gebelik haftası ve bebeğin kilosu SD grubunda daha düşük bulundu (sirasiyla $38,1 \pm 2,6$ vs $37,5 \pm 3,3$ hafta, $p<0,001$; $3215,1 \pm 513,9$ vs $3091,6 \pm 663,2$ gr, $p<0,001)$. Doğan bebeklerin cinsiyeti ve bebeklerin canlı ya da ölü doğumu arasında iki grup arasında fark saptanmadı $(p>0,05)$. Fakat birinci ve beşinci dakika Apgar skorları vajinal doğum grubunda daha yüksek bulundu. Ayrıca çoğul gebelik oranları SD grubunda daha yüksekti. İki grup Robson sınıflandırmasına göre karşılaştırıldığında nedenler arasında beklendiği gibi istatistiksel olarak anlamlı fark bulundu $(\mathrm{p}<0,001)$.

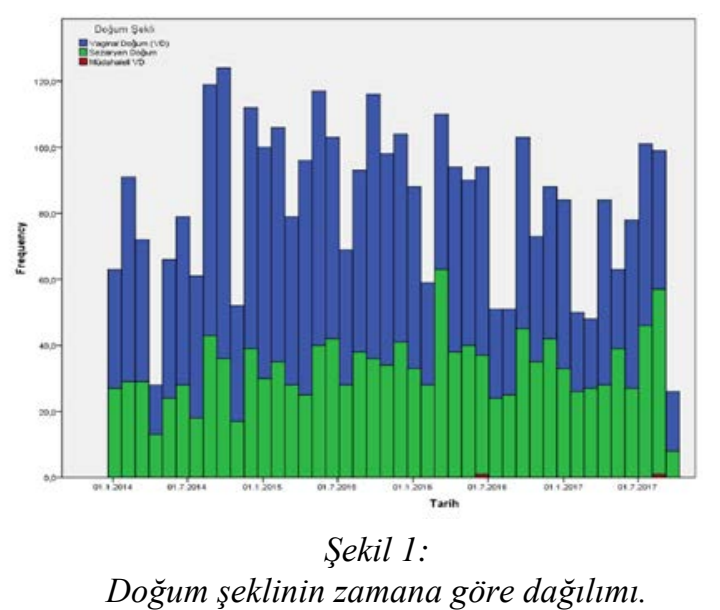

Tablo II'deki alt grup analizinde, SD'ların \%50,4'ü (696) mükerrer SD, \%49,6's1 (684) PSD'du. Ortalama öğrenim durumu, doğumdaki gebelik haftası ve bebeğin kilosu ile bebeğin cinsiyeti PSD grubu ile mükerrer SD grupları arasında benzerdi. Ancak ortalama 


\section{Primer Sezaryen Doğum Oranı}

anne yaşı, gravida, abortus, ölü doğum sayısı ile birinci ve beşinci dakika Apgar skorları PSD grubunda daha düşük bulundu (sırasıyla $31,7 \pm 6,5$ vs $28,6 \pm 7,1$ y1l, $<<0,001 ; 3$ (min: 1 - max: 12) vs 1 (min: 0 - max: 10), $\mathrm{p}<0,001$; 0 (min: 0 - max: 8) vs 0 (min: 0 - max: 5), $\mathrm{p}=0,001 ; 0$ (min: $0-\max : 8)$ vs 0 (min: $0-\max$ : 5), $\mathrm{p}=0,02 ; 8,1 \pm 1,2$ vs $7,8 \pm 1,5, \mathrm{p}=0,003 ; 9,2 \pm 1,1$ vs $8,9 \pm 1,5, p=0,002)$. Ancak maternal hipertansiyon ve diabetes mellitus ile perinatal komplikasyonlar her iki grupta benzerdi $(p>0,05)$. Ayrıca fetal anomali ve yenidoğan yoğunbakım ünitesine yatış oranları da iki grupta benzerdi $(\mathrm{p}>0,05)$.

Tablo I. Doğum yapan kadınların doğum şekline göre sosyodemografik özellikleri.

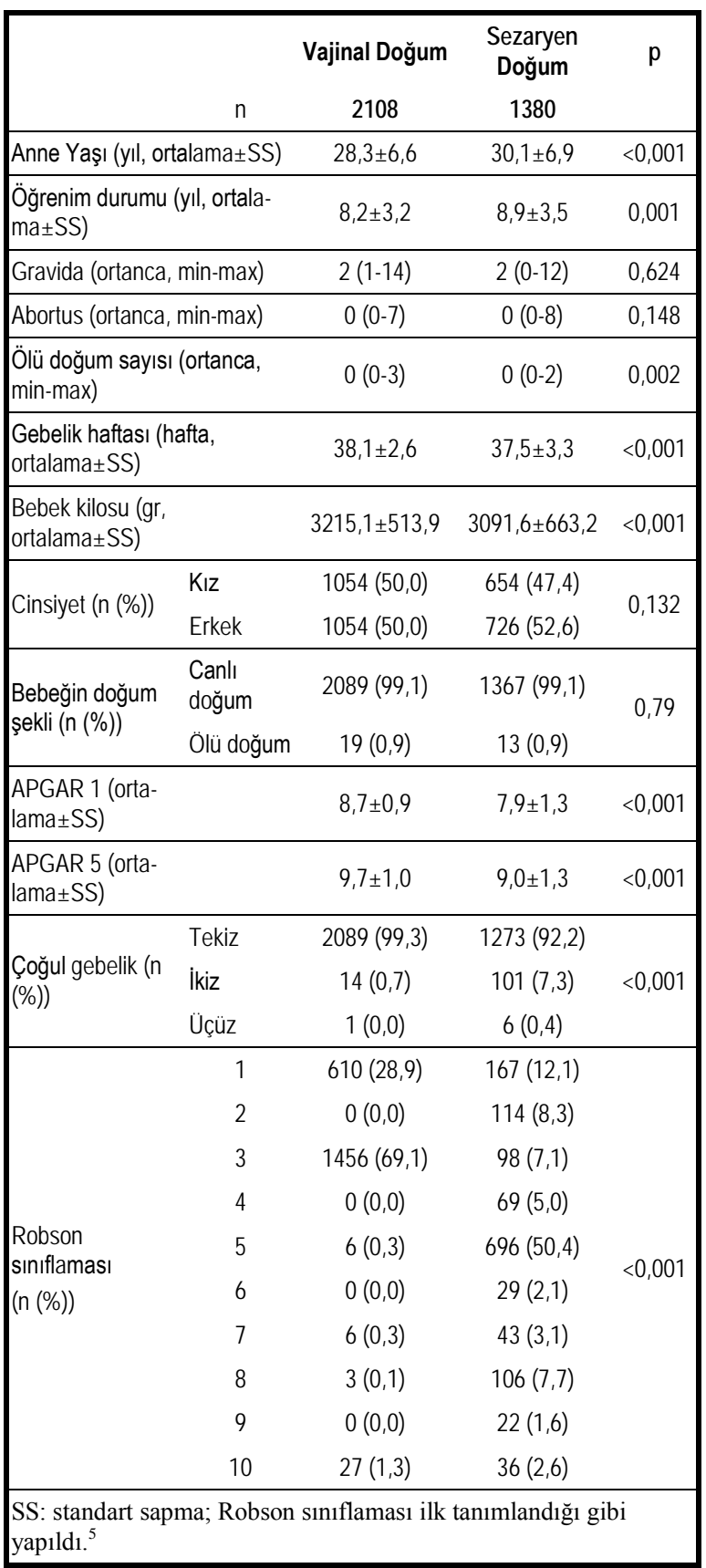

Tablo II. Primer sezaryen doğum yapan kadınların diğer sezaryen doğum yapan kadınlarla karşılaştırması.

\begin{tabular}{|c|c|c|c|}
\hline $\mathrm{n}$ & $\begin{array}{c}\text { Eski } \\
\text { Sezaryen } \\
\text { Doğum } \\
696\end{array}$ & $\begin{array}{c}\text { Primer } \\
\text { Sezaryen } \\
\text { Doğum } \\
684\end{array}$ & \\
\hline Anne yaşı (yıl, ortalama $\pm S S$ ) & $31,7 \pm 6,5$ & $28,6 \pm 7,1$ & $<0,001$ \\
\hline BMI & $27,7 \pm 4,7$ & $28,1 \pm 5,1$ & 0,141 \\
\hline $\begin{array}{l}\text { Öğrenim durumu } \\
\text { (yll, ortalama } \pm S S \text { ) }\end{array}$ & $8,9 \pm 3,6$ & $8,9 \pm 3,4$ & 0,947 \\
\hline Gravida (ortanca, min-max) & $3(1-12)$ & $1(0-10)$ & $<0,001$ \\
\hline Abortus (ortanca, min-max) & $0(0-8)$ & $0(0-5)$ & 0,001 \\
\hline $\begin{array}{l}\text { ölü doğum sayısı (ortanca, } \\
\text { min-max) }\end{array}$ & $0(0-2)$ & $0(0-2)$ & 0,020 \\
\hline $\begin{array}{l}\text { Gebelik haftası (hafta, } \\
\text { ortalama } \pm S S \text { ) }\end{array}$ & $37,4 \pm 2,8$ & $37,5 \pm 3,8$ & 0,720 \\
\hline Maternal Hipertansiyon (n (\%)) & $21(3,0)$ & $13(1,9)$ & 0.181 \\
\hline Maternal Diabetes mellitus ( $\mathrm{n}(\%)$ ) & $76(10,9)$ & $62(9,1)$ & 0,251 \\
\hline Preeklampsi-Eklampsi (n (\%)) & $11(1,7)$ & $18(2,6)$ & 0,248 \\
\hline Cerrahi alan enfeksiyonu (n (\%)) & $5(0,7)$ & $9(1,3)$ & 0,268 \\
\hline Re-laparatomi (n (\%)) & $1(0,1)$ & $2(0,3)$ & 0,553 \\
\hline Tüberküloz Peritonit (n (\%)) & $0(0,0)$ & $1(0,1)$ & 0,313 \\
\hline MNM-Kanama (n (\%)) & $2(0,3)$ & $3(0,4)$ & 0,640 \\
\hline MNM-Enfeksiyon (n (\%)) & $1(0,1)$ & $2(0,3)$ & 0,553 \\
\hline Bebek kilo (yıl, ortalama $\pm S S$ ) & $3077 \pm 550,6$ & $3092,3 \pm 768,4$ & 0,690 \\
\hline $\begin{array}{l}\text { Bebeğin doğum } \\
\text { sekli } \\
\begin{array}{ll}(\mathrm{n}(\%)) & \text { Ölü doğım doğum }\end{array}\end{array}$ & $690(99,1)$ & $677(99,0)$ & 0,756 \\
\hline Cinsiyet $(\mathrm{n}(\%)) \quad$ Erkek & $356(51,1)$ & $369(53,9)$ & 0,298 \\
\hline APGAR 1 (ortalama \pm SS) & $8,1 \pm 1,2$ & $7,8 \pm 1,5$ & 0,003 \\
\hline APGAR 5 (ortalama $\pm S S$ ) & $9,2 \pm 1,1$ & $8,9 \pm 1,5$ & 0,002 \\
\hline YDYBÜ yatış & $78(11,2)$ & $97(14,2)$ & 0,097 \\
\hline Fetal anomali & $11(1,6)$ & $142,0)$ & 0,516 \\
\hline
\end{tabular}

Tablo III'de ise PSD olan kadınların nullipar $(\% 61,5)$ ve multipar $(\% 38,5)$ olmasına göre endikasyonları karşılaştırıldı. Buna göre multipar gebelerde en sık PSD endikasyonları sirasıyla akut fetal distres (\%23,9), uzamış eylem $(\% 14,8)$ prezentasyon anomalisi $(\% 14,5)$ iken nullipar gebelerde ise uzamış eylem $(\% 28,5)$, akut fetal distres $(\% 21,4)$ ve baş pelvis

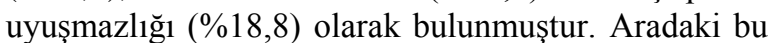
fark istatistiksel olarak anlamlıydı $(\mathrm{p}<0,001)$. 
Tablo III. Primer Sezaryen doğum endikasyonlarının pariteye göre dağılımı.

\begin{tabular}{|c|c|c|c|c|}
\hline & $\begin{array}{l}\text { Toplam } \\
\text { PSD }\end{array}$ & $\begin{array}{c}\text { İlk } \\
\text { gebelikte } \\
\text { PSD }\end{array}$ & $\begin{array}{c}\text { Multipar } \\
\text { gebede } \\
\text { PSD }\end{array}$ & $\mathrm{p}$ \\
\hline $\mathrm{n}$ & 684 & 421 & 263 & \\
\hline Akut fetal dissitres (n (\%)) & $153(22,4)$ & $90(21,4)$ & $63(23,9)$ & \\
\hline $\begin{array}{l}\text { Prezentasyon anomalisi (n } \\
(\%) \text { ) }\end{array}$ & $81(11,8)$ & $43(10,2)$ & $38(14,5)$ & \\
\hline $\begin{array}{l}\text { Baş pelvis uyuşmazlığı (n } \\
(\%) \text { ) }\end{array}$ & $115(16,8)$ & $79(18,8)$ & $36(13,7)$ & \\
\hline Uzamış eylem (n (\%)) & $159(23,2)$ & $120(28,5)$ & $39(14,8)$ & $0,001^{*}$ \\
\hline $\begin{array}{l}\text { Plasentasyon anomalisi } \\
(\mathrm{n}(\%))\end{array}$ & $38(5,6)$ & $7(1,7)$ & $31(11,8)$ & \\
\hline Çoğul Gebelik (n (\%)) & $92(13,5)$ & $63(14,9)$ & $29(11,0)$ & \\
\hline Kordon sarkması (n (\%)) & $7(1,0)$ & $2(0,5)$ & $5(1,9)$ & \\
\hline Makrozomi (n (\%)) & $39(5,7)$ & $17(4,0)$ & $22(8,4)$ & \\
\hline \multicolumn{5}{|c|}{$\begin{array}{l}\text { PSD: Primer Sezaryen doğum, *: p değeri nullipar ve multipar } \\
\text { gebeliklerdeki PSD nedenlerinin karşılaştırılmasını göstermek- } \\
\text { tedir. }\end{array}$} \\
\hline
\end{tabular}

Çalı̧̧ma grubumuzdaki gebelerden 6'sı $(\% 0,2)$ sezaryen sonrası vajinal doğum yaptı. Ayrıca yıllara göre SD oranları ve sayıları Şekil 2'de görülmektedir. Buna göre zaman içinde SD oranlarında bir miktar artış saptand1.

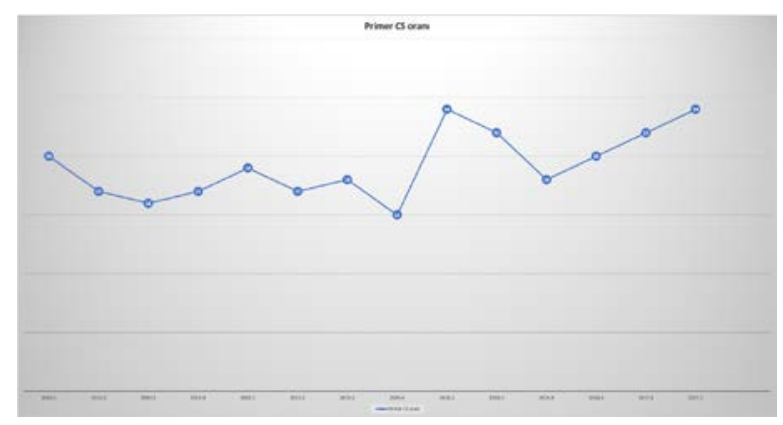

Şekil 2:

Primer Sezaryen doğum oranlarının zamana göre dağılımı.

\section{Tartışma ve Sonuç}

Tıbbı endikasyonlarla uygulandığında hayat kurtarıcı bir cerrahi müdahale olan SD, gereksiz kullanımda anestezi komplikasyonları, plasenta yapışma anomalileri, peripartum kanama, barsak ve mesane yaralanmaları, venöz tromboembolizm, cerrahi alan enfeksiyonu ve fetal solunum problemleri gibi artmış maternal ve fetal morbidite ve mortalite ile ilişkilidir ${ }^{7}$. Dolayısıyla SD sadece anne ve bebek sağlığ 1 için gerekliyse yapılmalıdır. Sunulan bu çalışmada da bu bilgi ile uyumlu şekilde sadece tıbbı endikasyonlarla SD uygulanırken, anne isteğine bağlı SD uygulanmamıştır.
İdeal SD oranı ile ilgili farklı görüşler bulunmaktadır. Dünya Sağllk Örgütünün (DSÖ) 1985'deki önerisin$\mathrm{de}^{8}$ SD oranlarının \%15'i geçmemesi söylense de günümüzde bu görüş değişmiştir. Kadınların yaşam tarzı değişiklikleri, beslenme özellikleri, sedanter yaşam, çocuk sahibi olma yaşının ilerlemesi, infertilite tedavisi ile elde edilen gebeliklerin artması, antenatal testlerin gelişmesi ve malpraktis davalarının artması gibi faktörler bu değişimin ana sebebi olabilir. Nitekim Molina ve ark yaptıkları çalışmada hem anne hem de neonatal morbidite ve mortaliteyi azaltmak için ideal SD oranının \%15-19 olması gerektiğini savunmuşlardır ${ }^{9}$. Bununla birlikte DSÖ 2015 y1lında belli bir SD oranına ulaşmak yerine sadece ihtiyacı olan kadınlara SD yapılmasını önermiştir ${ }^{10}$. Her merkezin hasta yükü ve profilinin farklı olması ve üçüncü basamak sağlık merkezlerinin daha çok riskli hastalık takip etmesi sebebiyle en uygun görüşün bu olduğunu düşünmekteyiz. Ayrıca toplumun yapısı, anatomik özellikler, beslenme alıskanlıkları, inanışları gibi birçok faktör de SD oranlarını etkileyebilmektedir. Bu oranları her toplum için aynı kabul etmek bu sebeplerle doğru olmayabilir. Sunulan bu çalışmada da tüm riskli hastaların sevk edildiği üçüncü basamak bir referans merkezinde sadece ihtiyacı olan gebelere SD uygulandığında PSD oranı \%19,6 ve toplam SD oranı \%39,6 olarak bulunmuştur. Bu oranların yüksek olmasının sebebi referans merkezi olmamızdan kaynaklanabilir.

Daha önce SD yapmış olan bir kadının sonraki doğumunu SD ile yapma ihtimali daha yüksektir. Bu kadınlarda SD sonrası vajinal doğum günümüzde hem malpraktis davaları hem de bir önceki SD nedenlerinin devam etme ihtimali sebebiyle daha az tercih edilmektedir. PSD ise bazıları sübjektif olmak üzere birçok endikasyonla uygulanmaktadır. Bundan dolayı SD oranlarını azaltmak için daha çok araştırılmalıdır. Çünkü PSD oranlarının azaltılması sadece bugünün SD oranlarını azaltmayacak, aynı zamanda gelecekteki mükerrer SD oranlarını da azaltacaktır. Bu sebeple, bu çalışmada PSD oranları ve bunları etkileyen faktörler araştırıldı. Çalışmamızda PSD endikasyonları incelendiğinde, sıklık sirasına göre nullipar gebelerde ilerlemeyen eylem, akut fetal distres ve baş pelvis uyuşmazlığı; multipar gebelerde ise akut fetal distres, uzamış eylem ve prezentasyon anomalisi PSD'un en sik sebepleriydi. Bu sonuçlar literatür ile uyumluydu ${ }^{11,12}$. Tıbbı endikasyonlar dışında PSD da yapılmaktadır. Yakın zamanda ülkemizden yapılan bir çalışmada SD kararlarının yaklaşık \%13, tubal ligasyon, doğum korkusu ve özel doğum günü ayarlamak için yapıldığı gösterilmiştir ${ }^{13}$. Sadece bu hasta grubunu vajinal doguma yönlendirmek PSD oranında \%13'lik azalma yaparken bu kadınların sonraki gebeliklerindeki mükerrer SD oranlarını da azaltacaktır. Kadın Hastalıkları ve Doğum uzmanları etik olarak anne isteği üzerine $\mathrm{SD}$ yapmak zorunda değildirler ${ }^{14}$. Bu sebeple çalışmamızda isteğe bağlı SD yapılmadığı için PSD oran- 


\section{Primer Sezaryen Doğum Oranı}

larımız bu çalıșmadan daha düşük bulunmuștur. Son zamanlarda yapılan bir çalışmada nullipar gebelerin travay yönetimindeki güvenli değişiklikler, maternal ve fetal komplikasyonlarda artma olmadan PSD oranlarını azaltabileceği gösterilmiştir ${ }^{15}$. Bu uygulamanın hastaların travay hakkındaki yeterli eğitimi ve yasal düzenlemelerle ile hayata geçirilmesi PSD oranını azaltacaktır

Yasal düzenlemeler ve toplumun bu konu hakkındaki eğitimi çok önemlidir. Çünkü bu konuda yaşanılan tecrübeler SD oranlarını etkileyebilir. Sunulan bu çalışmada zaman içinde SD oranlarının az da olsa artması bu bilgiyi desteklemektedir.

Çalışmamızın en önemli limitasyonu retrospektif doğasından kaynaklanmaktadır. Bu nedenle hangi durumda hangi endikasyonla SD kararının verildiği tam olarak bilinemeyebilir. Bununla birlikte bu çalışmada tek cerraha ait verilerin kullanılmış olması endikasyonlardaki standardizasyonu sağlamaktadır. Ayrıca çalışmamızda glokom, kalp yetmezliği ve kalp kapak hastalığı gibi değiştirilemeyecek maternal SD nedenleri çalışma dışında bırakılarak sadece değiştirebileceğimiz SD endikasyonları araştırılmıştır. Böylece hastanemizde SD oranlarına en çok katkı sağlayan kısmen değiştirebileceğimiz SD nedenleri belirlenebilmiştir.

Sonuçlarımıza göre isteğe bağlı SD yapılmadığında, tüm sevkleri alan tersiyer bir merkezde bile PSD oranı \%19,6 civarındadır. PSD'ların en sık sebebi uzamış eylem, fetal distres, baş pelvis uyuşmazlığı ve perzentasyon anomalisi gibi kısmen düzeltilebilecek nedenlerdi. Bu sebeple malpraktis davaları ile ilgili gerekli yasal düzeltmeler sağlandıktan sonra PSD'un bu nedenleri yeniden gözden geçirilerek SD oranları daha da azaltılabilir. Böylece hem PSD oranı hem de mükerrer SD oranı azaltılabilir.

Etik Kurul Onay Bilgisi:

Onaylayan Kurul: Adıyaman Üniversitesi Girişimsel Olmayan Klinik Araştırmalar Etik Kurulu

Onay Tarihi: 18.12 .2018

Karar No: 2018/9-17

Arastırmacı Katkı Beyanı: Fikir ve tasarım: M.B.; Veri toplama ve işleme: M.B.; Analiz ve verilerin yorumlanması: M.B.; Makalenin önemli bölümlerinin yazılması: M.B.

Destek ve Teşekkür Beyanı: Bu çalışma herhangi bir kurumkuruluş-kiși tarafindan desteklenmemiștir.

$\mathrm{Bu}$ çalışmaya verilerin sağlanmasındaki yardımlarından dolayı Mahmut Özbakırcı'ya çok teșekkür ederiz.

Çıkar Çatışması Beyanı: Makale yazarının çıkar çatışması beyanı yoktur.

\section{Kaynaklar}

1. Vogel JP, Betran AP, Vindevoghel N, et al. Use of the Robson classification to assess caesarean section trends in 21 countries: a secondary analysis of two WHO multicountry surveys. Lancet Glob Health. 2015; 3(5): e260-70.

2. Martin JA, Hamilton BE, Osterman MJK, et al. Births: Final Data for 2018. Natl Vital Stat Rep 2019; 68: 1.2

3. Boerma T, Ronsmans C, Melesse DY, et al. Global epidemiology of use of and disparities in caesarean sections. Lancet 2018; 392: 1341

4. Solheim K, Esakoff $\mathrm{T}$, Little $\mathrm{S}$, et al. The effect of cesarean delivery rates on the future incidence of placenta previa, placenta accreta, and maternal mortality. J Matern Fetal Neonatal Med 2011; 24: 1341-6.

5. Caughey AB, Cahill AG, Guise JM. Safe prevention of the primary cesarean delivery. American College of Obstetricians and Gynecologists (College); Society for Maternal-Fetal Medicine. Am J Obstet Gynecol. 2014; 210(3): 179-93. doi: 10.1016/j.ajog.2014.01.026.

6. Robson MS. Can we reduce the caesarean section rate? Best Pract Res Clin Obstet Gynaecol 2001; 15: 179-94.

7. Mascarello KC, Horta BL, Silveira MF. Maternal complications and cesarean section without indication: systematic review and meta-analysis. Revista de saude publica. 2017; 51: 1-12.

8. World Health Organization. Apropriate tecnology for birth. Lancet. 1985;436-7.

9. Molina G, Weiser TG, Lipsitz SR, et al. Relationship Between Cesarean Delivery Rate and Maternal and Neonatal Mortality. JAMA. 2015; 314(21): 2263-70. doi: 10.1001/jama.2015.15553.

10. World Health Organization. WHO statement on caesarean section rates. April 2015. WHO/RHR/15.02. (Accessed on December 25, 2020.)

11. Karbancığlu Cantürk F, Songur Dağlı S. Multipar gebelerde primer sezaryen endikasyonları. Bozok Tıp Derg 2018; 8(4): 69-73).

12. Caughey AB, Cahill AG, Guise JM, et al. Safe prevention of the primary cesarean delivery. AJOG. 2014; 210(3): 179-193.

13. Toker E, Turan Z, Sönmez MO, et al. Why have the numbers of cesareans increased globally? The factors that affect women's decisions about cesarean delivery in Turkey, The Journal of Maternal-Fetal \& Neonatal Medicine, 2020; 33(20): 3529-3537, DOI: $10.1080 / 14767058.2019 .1644311$.

14. Norwitz ER. Cesarean delivery on maternal request. In: UpToDate, Lockwood CJ (Ed), UpToDate, Barss VA. (Accessed on December 25, 2020)

15. Thuillier C, Roy S, Peyronnet V, et al. Impact of recommended changes in labor management for prevention of the primary cesarean delivery. Am J Obstet Gynecol 2018; 218: 341.e1-9. 
